\section{Fighting schizophrenia and its stigma}

\section{A new World Psychiatric Association educational programme}

NORMAN SARTORIUS

The World Psychiatric Association (WPA) has initiated the development of a new educational programme on schizophrenia, with particular emphasis on its social aspects including stigma and discrimination, on the possibilities for its effective and humane treatment, and on the rehabilitation of people who have suffered from schizophrenia.

\section{OBJECTIVES AND TARGETS}

The main objectives of the WPA programme are to develop an educational package to support the comprehensive management of schizophrenic illness worldwide, and to design and prepare materials enhancing awareness of the public health importance of schizophrenia and helping to reduce stigma and discrimination linked to it.

In addition to the general public, target audiences will be families and patients, mental health workers, health workers who also deal with mentally ill people, and community leaders. General practitioners will receive particular attention.

\section{DESIGN}

The WPA programme will be sensitive to differences between countries and cultures. It will combine internationally and locally produced materials with commentaries by leading experts and non-governmental organisations from individual countries.

The programme will be coordinated by a Steering Committee and developed by four working groups; it is expected to last three years. The programme will include the production of materials, their field testing and adaptation to different socio-cultural settings. The materials for the programme are expected to be in the form of a core text, to be prepared in English with subsequent multiple translations, together with slides, transparencies and handouts for teachers; local commentary materials (videos); satellite television broadcasts; interactive CDI or videos; patient vignettes; and sample materials for patients, families and general practitioners.

Instructions on the use of modern communication technology will be provided. The programme will design methods and propose indicators for the evaluation of its impact. Distribution of the programme on the Internet will be considered.

\section{YOUR CONTRIBUTION}

On behalf of the Steering Committee, I will welcome contributions.

\section{ACKNOWLEDGEMENT}

This WPA educational programme is supported by an unrestricted educational grant from Eli Lilly \& Company.
NORMAN SARTORIUS, MD. Département de Psychiatrie. Université de Genève, H. U. G., 16-18 Bd de St Georges, 1205 Gèneve, Switzerland

(First received 8 January 1997, accepted 9 January 1997) 